\title{
Rethinking Niklas Luhmann's Theory of the Phylogenesis and Ontogenesis of Language in Light of Systemic-Functional Linguistics
}

\author{
Santiago Gabriel CALISE \\ National Council of Scientific and Technical Research, Gino Germani Research \\ Institute, Faculty of Social Sciences, University of Buenos Aires, Argentina \\ c_santiago_g2000@yahoo.com.ar
}

This paper deals with the problems of phylogenesis and ontogenesis of language, departing from Niklas Luhmann's general hypothesis of the co-evolution of psychic and social systems. Regarding phylogenesis, the focus in Luhmann's theory was placed on the "pre-linguistic medium of communication" constructed by gestures, which would have been the element that stimulated the evolution of language. This sort of communication allows for the emergence of a certain social order. Here, the problem was the impossibility of identifying this social order by one of the primary forms of societal differentiation. An attempt was made to interpret in which societal contexts pre-language "emerges". In order to do this, the author resorted to Michael Halliday's systemic-functional linguistics. Concerning ontogenesis, the attention was directed to the concepts of action and experience. The point of departure was Ilja Srubar's criticism of Luhmann's theory of language, according to which the acquisition of language can be thought of as a process of translating action schemes into linguistic ones. This implies a nativist vision of language discarded by Luhmann and also by Halliday. The latter indicated that it is impossible to talk about translating non-linguistic and pre-linguistic cognition schemes into linguistic form because there is no model of experience previous to the linguistic categories. In addition, an attempt was made to show that systemic-functional linguistics can be useful to fill the gap regarding the ontogenesis of language left by Luhmann's systems theory.

Key words: language in systems theory, Luhmann, ontogenesis of language, phylogenesis of language, the action/experience distinction, systemic-functional linguistics 


\section{Introduction}

This paper deals with Luhmann's interpretations of the phylogenesis and ontogenesis of language. Even if Luhmann did not treat the topic with as much profundity as he did others (such as communication, society, double contingency, etc.), the concept of language takes up a central place in Luhmann's systems theory as it is the element that "connects" consciousness and communication. Despite its importance, only Srubar (2005) has considered this topic in his general assessment of Luhmann's concept of language. We will discuss one of Srubar's critiques regarding the relationship between action and language. In addition to Srubar, we can also mention Michael Urban's (2009) study of the psyche, which discussed in depth Luhmann's conceptualisations of the psychic system. Urban introduces Alfred Lorenzer's and Julia Kristeva's ideas in order to account for the pre-linguistic and linguistic development of the psyche. Nevertheless, Urban does not make clear how he reconciles systems theory with these interpretations of language.

In order to assess Luhmann's conceptualisations of the emergence of pre-linguistic communication (phylogenesis) and the relationship between action and language (ontogenesis), we will observe systems theory from the systemic-functional linguistic point of view. The aim is not to achieve convergence between both theories but, instead, to identify some blind spots and weaknesses in Luhmann's theorising. We find that systemic-functional linguistics are particularly appropriate to carry out this task, as Michael Halliday $(1978,2003)$ has devoted an important part of his work to the study of protolanguage in children and the passage into adult language. This detailed analysis has been used as a basis for a phylogenetic interpretation of the emergence of language. In addition, these phylogenetic studies have been complemented with evidence from other disciplines, such as anthropology, neuroscience, psychology, biology, etc.

Departing from a brief exposition of Luhmann's and Halliday's conceptualisations of language, this criticism will concentrate on two points. Firstly, attention will be focused on the emergence of language and its societal context. Related to this question of the origin of language, we will reintroduce the concepts of action and experience through Srubar's criticism in order to deal with the problem of the ontogenesis of language. We will leave for another paper the assessment of language as a medium for the structural coupling between psychic and social systems. 


\section{The concept of language in systems theory and in systemic-functional linguistics}

\subsection{Language in Luhmann's systems theory}

Systems theory departs from the system/environment distinction (Luhmann, 1995a). A system can survive if it can preserve its boundaries with the environment. Unlike machines and organisms, social systems, as psychic systems, utilise the medium of meaning as a substratum to develop their operations. Processing meaning implies that the system works by continually remodelling the difference between actuality and possibility. As a result, meaning is understood as the continuous actualisation of possibilities. In order for a social system with these traits to emerge, it needs to overcome the situation of double contingency. The simplest form of this event entails the encounter of two psychic systems (alter and ego). As each of them defines its behaviour by self-referential operations, both tend to presuppose the same regarding the other. This leads each to treat the other as an alter ego. In this relationship emerges a new order that cannot be reduced to either of the systems that produced it.

A social system reproduces itself through only one sort of operation: communication. In this analysis, communication is seen as the synthesis of three selections: utterance (Mitteilung), information and understanding (Verstehen) (Luhmann, 1995a, 2012). Utterance enunciates information, while information indicates an event that selects states of a system. This means that information is not a simple message. Ultimately, understanding is not a psychic experience but the act of distinguishing and maintaining the difference between utterance and information. When ego can draw that distinction, there is communication. Beyond the unity of communication, there is the possibility to accept or reject communication, whose value lies in its capacity to connect communications. In order for communication to become a process, single communication events must be ordered by themes. Nevertheless, communication also faces three improbabilities (Luhmann, 1995a): the improbability of understanding, the improbability of reaching the addressee and the improbability of success such that the communication is accepted and followed. The solutions for these improbabilities are: language, the media of dissemination and symbolically generalised communication media. In this analysis, language is interpreted as a medium, which increases the decipherability of communication beyond the sphere of perception. 
As language is a medium that "relates" social and psychic systems as well as one that intensifies understanding, it is necessary to introduce the concepts of interpenetration and structural coupling. The first indicates that interpenetrating systems enable each of the systems to introduce its own already-constituted complexity into the other.

It is possible to suppose that the weakness of the concept of interpenetration, partially accepted by Luhmann (2004), has brought Luhmann to look for a theoretical alternative that could link better with his conceptual assemblage. For this reason, Luhmann has resorted to another of Humberto Maturana's categories (Maturana, 1982): structural coupling. With this concept, Luhmann (1995b) expected to exclude every possible combination between the operations of both systems, trying to exclude an operational coupling. This is expressed with the Maturanian formula, according to which structural coupling is orthogonal regarding autopoiesis.

Concerning social systems, these can only be structurally coupled to psychic systems, ${ }^{1}$ which implies that communication can only receive permanent irritations from consciousness. ${ }^{2}$ If these irritations become stable, it is possible that they will guide the development of structures in a certain direction. From another point of view, the structural coupling translates analogical relations into digital ones. In spite of this conceptual turn, Luhmann, in his book Die Gesellschaft der Gesellschaft (1997, 2012, 2013), adds that it is possible to talk about interpenetration when the coupled systems co-evolve.

Language plays an essential role in this context, as it is the medium that allows the structural coupling (but not the interpenetration) between social and psychic systems. In his book Social Systems (1995a), Luhmann indicates that, on the one hand, language intensifies understanding beyond what is actually perceptible. On the other hand, the sociologist adds that language amplifies infinitely the repertoire of understandable communication, as practically every event can be treated as information. Finally, Luh-

\footnotetext{
${ }^{1}$ For a reformulation of the concept of structural coupling between psychic and social systems, cf. Baraldi (1993). Baraldi recombines the concepts of interpenetration and structural coupling at the same time that he distinguishes between the structures of the psychic and social systems.

${ }^{2}$ Because of the operational cloture of autopoietic systems, the environment cannot intervene in the operativity of the system. This implies that the environment can only cause irritations or perturbations to the system. These irritations are internal constructions that are the result of the contrast between the events and the system's structures.
} 
mann emphasises that language ensures the reflexivity of the system, which entails the possibility of self-steering.

As previous indicated, in Social Systems language is interpreted as a medium that solves one of the improbabilities of communication. Nevertheless, Luhmann does not delve into the particularities. Years later, in Die Gesellschaft der Gesellschaft (1997) and in an article entitled "Sign as Form" (1999), he proposes two different interpretations of language that are not completely compatible. In Die Gesellschaft der Gesellschaft, Luhmann indicates that linguistic communication is a processing of meaning in the phonic medium. As a result, the medial substratum of language will be meaning/sound. In this context, Luhmann defines meaning as that which "is not the sound but determines what sound is to be selected if this meaning and no other is to be spoken about", while "the sound is not the meaning, but with this not-being, as it were, it determines what meaning is spoken about in each case" (2012: 128). This processing of meaning in the phonic medium produces the condensation of sounds into words. Naturally, in order for this process to take place, as Luhmann (2012, 2013) himself reveals, one needs grammar and - alluding to Noam Chomsky but rejecting the innatist connotations of the concept - deep structures. What Luhmann does not clarify is where such grammar and deep structures lie and how they operate in the process previously described. As each distinction implies distinguishing / indicating, and only psychic and social systems operate in the medium of meaning, the process due to which a meaning is distinguished and a sound is indicated cannot be something other than the result of a psychic or social operation. An additional problem is establishing how grammar and deep structures work.

Consequently, words will be the loosely coupled elements of the medium of language. These words, in turn, will condense into phrases, which will be the forms of language according to the distinction phrases/ words. Therefore, phrases come to confirm and condense the meaning of each phrase, condemning to oblivion those that are not utilised for a long time. In spite of this, meaning/sound, just like phrases/words, are neither structures, nor elements, nor operations of any of the systems that process meaning. Simply, these two distinctions constitute the unity of the difference of the form of the medium of language.

On the other hand, Luhmann (1999) also integrates semiologic categories into his analysis, specifically the Saussurean concept of sign, conceived 
as the distinction between signifier and signified (De Saussure, 1995). As forms, signs exist exclusively in the operations of a system that utilises them - and never in the environment. These signs have their own characteristics, one of which is that they must be isolated. In this sense, they must be distinguishable and not confused, which makes it possible to use them repeatedly as discernible units. As a result, they can be remembered. In addition, signs must be redundant, providing a surplus of meaning, which allows the anticipation of the next sign. Finally, following the father of semiology, signs must be arbitrary, but not in the sense of being freely selected or independent of any structure or context. On the contrary, arbitrariness is present in the fact that the relationship between signifier and signified is unmotivated, and thus it has no parallel in "reality". As a consequence, it does not imitate nature.

The main difference between the distinction between sound/meaning and signifier/signified is that the Saussurean signifier is not merely a sound but an acoustic image, which is a psychic trace (De Saussure, 1995). The sound that Luhmann $(2012,2013)$ references seems to be material sound (to use Ferdinand de Saussure's words), which is completely independent of any psychic image. In this way, this medium of language can find its abode in a terrain independent of the psychic and social realms. On the contrary, the problem that Luhmann (2004) finds in the theory of sign is that a sign indicates an internal state of the speaker. Here, the two theories seem to be incompatible. Making an interpretative effort, it is possible to reconcile the meaning and the signified. Meaning remains a more abstract category, as the signified is only the concept. Nevertheless, a concept can be considered to be a particular condensation of meaning, and, as such, it would be a particular type of form in that medium. These inconsistencies in Luhmann's approach to language show that it is still necessary to rethink language in the context of systems theory.

According to Luhmann, language ensures the regularity and continuity of the autopoiesis of society. This means that communication would have been improbable without the contribution of language. For systems theory, the questions regarding the ontogenesis and the phylogenesis of language can be answered by the concept of co-evolution between social and psychic systems (Luhmann, 1995a, 2012, 2013). This implies that the appearance and development of language find their contexts in the general evolution of society, but it also means that psychic systems acquire language in this 
special relationship with society. As a result, this concept of co-evolution accounts for the phylogenetic and ontogenetic dimensions of language. Nevertheless, co-evolution is a very general category and provides merely a conceptual context within which to focus research.

\subsection{The systemic-functional approach to language}

Since systems theory does not provide definitions of the processes of ontogenesis and phylogenesis of language, we resort to Halliday's systemicfunctional linguistics. Halliday $(1998,2004)$ understands that phylogenetic time is the time of the evolution of language as a system and of the evolution of its particular subsystems. This evolution manifests itself, for example, in the emergence of particular registers, such as scientific discourse. In contrast, ontogenetic time expresses the development of the individual speaker. This individual experience is, for Halliday (1998), one of growth and not of evolution, following the cycles of growth, maturation and decay. Halliday's research focuses mainly on the ontogenesis of language, trying to interpret how children begin to exchange meanings, how they construe a semantic system that slowly approximates the language of adults and how, while they develop that system, they use it to make sense of their experiences (Halliday, 2003). Departing from the findings on the ontogenetic dimension, Halliday and Matthiessen (1999) hypothesise that the history of the individual speaker recapitulates some of the evolutionary progression along epigenetic lines. As we will later see, Christian Matthiessen (2006) has tried to support this hypothesis with the limited information that we have about those remote periods of hominization.

Halliday (1978) interprets language as a system of choices organised in three strata: semantics, grammar (or lexico-grammar) and phonology. These strata constitute a net of options and elections, in which each level "realises" the others so that the selections made at the lexico-grammatical level restrict the field of options of what one can choose at the semantic level. At the same time, language is structured to make three kinds of meanings: ideational, interpersonal and textual. ${ }^{3}$

According to Suzanne Eggins (2004), this theory understands that a text is any passage that forms a unified whole, and the property that permits for a distinction between text and non-text is called texture. As a result, the texture is that element that holds the clauses of a text together to

\footnotetext{
${ }^{3}$ For a definition of these three kinds of meanings, see subsection 2.3.
} 
give them unity. In addition, texture involves the interaction of coherence (the text's relation to its extra-textual context) and cohesion (the way the elements within a text bind it together as a unifying whole).

The functional analysis suggests (Eggins, 2004) that each dimension of social context is related in predictable and systematic ways to each type of meaning. Thus, language is "naturally" related to the structures of social life. As a consequence of this, if genres are different ways of using language, it should be found that speakers make different lexico-grammatical choices according to the different purposes that they would like to achieve. Consequently, the texts of different genres will reveal different lexico-grammatical choices.

\subsection{The concepts of meaning in Luhmann's and Halliday's theories}

As the concept of meaning will be relevant in the following sections, it is important to show the similarities and differences between Luhmann's and Halliday's conceptualisations. First of all, there is a problem with the translation of Sinn, which was rendered into English with "meaning". Meaning is a better translation for Bedeutung. In fact, Halliday's meaning is rendered into German as Bedeutung and not with Sinn. This is a first sign that the authors are referring to different ideas.

Luhmann understands meaning (at least in Social Systems) as a product of the co-evolution of psychic and social systems. For both systems, meaning is the form of their complexity and self-reference, and it represents a surplus of references to other possibilities of experience and action. ${ }^{4}$ Meaning is defined as a medium in which form is the distinction between actuality and potentiality. This implies that actualised meaning is and remains possible, and possible meaning remains actualisable (Luhmann, 2012, 2013). In Spencer-Brownian (1972) language, this means that this form provides for the re-entry of the distinction into that which it distinguishes. As a result, meaning contains a copy of itself on both sides of its form. The re-entry allows meaning to be a self-regenerating medium for the ongoing selection of particular forms.

In contrast, Halliday states that there are four types of systems (physical, biological, social and semiotic systems), and the system of meaning (or

\footnotetext{
${ }^{4}$ In Die Gesellschaft der Gesellschaft (1997, 2012, 2013), Luhmann avoids the reference to experience, action and intentionality when he unfolds his concept of meaning.
} 
semantics) is one of the systems that constitutes the semiotic system. Even if the label "systemic" is part of the name of this theory, it is not evident what "system" means for Halliday. In a paper published in 1966 (Halliday, 2005e), the English linguist says that the relation of system to paradigm is analogous to that of structure to syntagm. ${ }^{5}$ As a result, a system would be a representation of relations on the paradigmatic axis, and thus the grammatical description of a linguistic item involves a structural and a systemic component. This definition is clear and has evident points of contact with the linguistic tradition, but it only explains the meaning of "system" in a linguistic context. Halliday does not propose any general systems theory, as Luhmann does, that can explain what constitutes a physical, a biological and a social system. Halliday (1998) only says that physical systems are just physical systems. Biological systems are physical systems with the added component of "life". Social systems are biological systems with the added component of "value". Finally, semiotic systems are social systems with the added component of "meaning". As a result, meaning is a social and psychic process, but it only emerges with the appearance of a semiotic system.

Returning to Luhmann (1995a), the possibility to experience or enact meaning is determined in operations of psychic or social systems. Meaning gives form to both psychic and social operations, as they are accomplished on the basis of meaning. As a result, meaning entails selection, as selection and operation are the same process. Meaning produces an excess of possibilities, but it compels the system to actualise only one. At the same time, through reference (Verweisung) to everything that is not actual, meaning allows one to indicate everything that is not actual.

In a similar vein, Halliday understands that meaning is the product of choice (2005a). For the English linguist (Halliday, 2005c), language constitutes human experience, as grammar transforms experience into meaning. In addition, language constitutes social processes and the social order, as through meaning grammar brings about the process and the order. Experience is construed twice: semantically and lexico-grammatically (Halliday

\footnotetext{
${ }^{5}$ The concept of structure is also very vague in Halliday's theorising. The linguist does not provide an abstract definition of structure as Luhmann does. Referring to the three components of meaning, he indicates (2005e) that to each component corresponds a type of structure. As a result, "experiential structures tend to be more elemental in character, interpersonal structures tend to be prosodic and textual structures tend to be culminative or periodic" (Halliday, 2005e: 209). However, this concrete description of each type of structure does not allow us to deduce a general concept.
} 
and Matthiessen, 1999). Both Halliday and Luhmann interpret meaning as a construction. The difference is that Halliday has a "humanist" vision, since the one that transforms experience into meaning is the human being who possesses the language; for Luhmann, both social and psychic systems operate in the medium of meaning, actualising continuously its possibilities. Whereas for Luhmann communication is in the foreground and language holds a marginal position, for Halliday language plays the central role.

The last point of comparison is the dimensions of meaning. Luhmann (1995a) identifies three meaning dimensions: the fact dimension, the temporal dimension and the social dimension. The German sociologist indicates that the fact dimension refers to all objects of meaningful intention (in psychic systems) and themes of meaningful communication (in social systems). This dimension distinguishes between something as yet indeterminate and something else as yet indeterminate. Regarding the temporal dimension, its primary distinction is that between before and after, which is extended into the past and the future. This means that this dimension becomes independent of that which is immediately experienced. The social dimension is connected with that which one accepts as an alter ego. This implies that this alter ego becomes relevant to all objects and all themes.

Halliday (2005b) also identifies three components of meaning, as mentioned in subsection 2.2. The ideational component interprets language as representation. Here, the semantic system becomes the expression of experience. The second component is the interpersonal, in which language is viewed as interaction. In this, the semantic system expresses the speaker's intrusion into the speech event (i.e., one's attitudes, evaluations and judgments; one's expectations and demands; the role that one is taking in the communication process and the role that one is assigning to the hearer). The textual component indicates that the speaker structures meaning as text, organising each element as a piece of information and relating it to that which has gone before.

This decomposition of meaning into dimensions or components shows some similarities: between the fact dimension and the ideational component and between the social dimension and the interpersonal component. Despite these similarities, the analysis carried out in this section expresses that the authors are referring to different phenomena, not just different interpretations of meaning. Luhmann's concept of meaning is placed in a higher degree of abstraction, as it precedes all the processes that Halliday describes. 


\section{The origin of language: Luhmann's hypothesis on the phylogenesis of language viewed through systemic-functional linguistics}

\subsection{Luhmann's hypothesis regarding the pre-linguistic communication medium}

As we have stated in the previous section, Luhmann does not provide any systematic explanation of the phylogenesis of language. However, he expressed his hypothesis about the emergence of language in a long paragraph in Die Gesellschaft der Gesellschaft, which is quoted in the appendix. According to Luhmann, language ensures the regularity and continuity of the autopoiesis of society. This means that communication would have been very improbable without the contribution of language. For systems theory, the question regarding the ontogenesis and the phylogenesis of language can be answered by the concept of co-evolution between social and psychic systems. This implies that the appearance and development of language find their contexts in the general evolution of society. Nevertheless, coevolution is a very general category, which only provides a conceptual context in which specific research regarding phylogenesis can find its place. However, it is not the answer to the problem.

The point of departure of Luhmann's $(2012,2013)$ hypothesis referred to phylogenesis as a pre-linguistic communication medium. This medium could have profited from bodily movement, and/or it could have been a recursive sequence of gestures, which are signals, not signs. As Luhmann quotes George Herbert Mead, we can assume that the German sociologist refers here to Mead's (1972) concept of "conversation of gestures". This connotes non-conscious communication. According to Mead, language (constituted of significant symbols) and communication develop from this conversation of gestures, passing from non-significant to significant interaction. From Luhmann's text, we can deduce that this conversation of gestures is episodic; it is constituted of signals, which are not signs (as they do not point to something else). Signs are species-specific and of very limited use, although they activate anticipatory reactions. This situation allows the emergence of "relatively complex social orders". As there is a social order, we can assume that there is communication. Luhmann $(2012,2013)$ identifies some conditions (reactive patterns of behaviour have to be reapplied to their own outcomes), limitations (the potential for form building was limited) and some traits (there were hierarchies and individual partner 
preferences) of this social order. From this extremely brief description, we cannot be assured whether Luhmann is thinking of that which he calls a segmentary society or a preceding social order.

After this reference to that particular social order, Luhmann returns to pre-language. In this context, perception of perception and the perception of being perceived are the most important preparations for the evolution of language. Luhmann $(2012,2013)$ indicates something very important: In a context dominated by the conversation of gestures, metacommunication would not be possible. This is a crucial point, as this is a condition for the autopoietic closure of the social system. Finally, Luhmann concludes this paragraph by suggesting that gestures and sounds, as signs, played a role (we do not know which) in the take-off of the evolution of language. Luhmann seems to be convinced about the impossibility of metacommunication, but he does not dare to state as emphatically that autopoiesis would also be impossible. The survival of the social system seems to be tied to the survival of a particular group of human beings who take part in communication and probably share some fundamental knowledge. This means that the survival of the social system is not indifferent to the generational change. Returning to the problem of the form of societal differentiation, if we suppose that in this primitive situation there are social systems because we admitted that there was communication - but cannot assume that these systems are autopoietic, we can conclude that we are not facing a segmentary society. Nevertheless, this state of affairs cannot be thought of as isolated communicative episodes between solitary human beings. As we have previously seen, if there are hierarchies, then this pre-linguistic social situation must have developed some structures. As a result, we could be in a transitional moment, which will be overcome with the appearance of language, possibly the guarantor of metacommunication and autopoiesis. In addition, if we have noticed that this social order developed particular hierarchies and structures, it is quite difficult to believe that it relies so much on the survival of a particular generation of human beings and that this conversation of gestures is merely episodic.

In section 2, in referring to language as a medium, we have seen that Luhmann $(2012,2013)$ notes fleetingly that in order to condense sounds and meanings into words ready to be used, grammar and deep structures are necessary. In a very important footnote on this point (footnote number 36), Luhmann indicates that: "This is not to say that I agree with 
Chomsky's thesis that such structures must be innate, because the speed of language acquisition cannot otherwise be explained. [...] What Chomsky seeks to explain in terms of innateness, I explain in terms of structural coupling and the consequent intensification of (origin-specific) irritations and irritation processing" (2012: 338). Luhmann rejects here the idea of a "universal grammar". In order to account for the ease with which children acquire the grammar of their first language and the ability of adults to effortlessly use it, Chomsky hypothesises that "all human brains come with a built-in language organ that contains this language blueprint" (Deacon, 1997: 35). Thus, Luhmann rejects innatism and explains the acquisition of grammar (and language in general) through structural coupling or, as we have already said, by means of the co-evolution of social and psychic systems. Some authors, such as Terrence Deacon (1997), would add to this the co-evolution of the brain and language. Nonetheless, Luhmann does not propound any particular hypothesis regarding the appearance or construction of grammar in this co-evolutionary process.

\subsection{The systemic-functional hypothesis on the phylogenesis of language}

Following Christian Matthiessen (2006), we can better illuminate these problems of the "evolution" and "emergence" of language. This author proposes a radical approach to this topic, departing from the hypothesis that ontogenesis recapitulates phylogenesis. This means that the ontogenetic phases of language development constitute a model of phylogenesis. At this point, Matthiessen indicates that even if the reader does not want to accept that highly controversial hypothesis, the adoption of the ontogenetic model represents a scheme of the way in which semiotic complexity can develop from a simple primary semiotic system. Moreover, this model points to no future goal; instead, it shows how each stage of development is functional in its own right and how more complex semiotic patterns evolve out of existing ones.

Regarding the relationship between ontogenesis and phylogenesis, Matthiessen (2006) also indicates that there is an important difference between them, as semiotic phylogenesis does not involve modelling and scaffolding by elder members. As a result, some processes that can be quite compressed in ontogenesis could have been extended in phylogenesis.

Matthiessen departs from Halliday's (2003) analysis of the acquisition of language in order to identify the three phases of the evolution of this 
process. The first one is protolanguage, which is bistratal (content/expression) and microfunctional (indicating that the function equals use and is directly tied to context). At the same time, based on anthropological research, Matthiessen locates this phase from before the emergence of the hominid line up to about the appearance of Homo habilis. ${ }^{6}$ In addition, Matthiessen states that protolanguage is very old and can be a semiotic potential shared with apes in the wild. Halliday (2006) suggests that protolanguage can be used to point, but one cannot use it to name things, refer to things, make generalisations or isolate and combine independent variables. In addition, it does not allow users to open a dialogue, construct a narrative or instigate any structured form of discourse. With protolanguage, one can reach the point of stringing signs together, even if this process is not quite common. In order to advance to a higher-order semiotic, it is necessary to introduce a stratum of grammar, which expands the meaning potential to an indefinite extent.

Phase II is a transitional tristratal model, which enjoys the emergence of lexico-grammar "as a new stratum within content and of a phonological system out of the vocal 'postures' of protolanguage" (Matthiessen, 2006: 48). However, microfunctions turn into two macrofunctions: mathetic and pragmatic. One of the most important traits of phase II is the emergence of early types of narratives. From an anthropological point of view, this period is identified with the time of Homo erectus and archaic Homo sapiens. From a sociological perspective, this phase may coincide with the beginning of family-level group societies of approximately 25 members. Thus, the transition to local group societies seems to take place well into the next phase.

In phase III (Matthiessen, 2006), language becomes fully tristratal (semantics, lexico-grammar, phonology) and is expanded later by graphology at the level of expression and by grammatical metaphor in the relationship between semantics and lexico-grammar. However, language transitions from being macrofunctional to being metafunctional. From an anthropological standpoint, the beginning of this phase took place towards the end of the archaic Homo sapiens, and the phase developed further during the time of modern Homo sapiens. Historically, this phase starts with the "Upper

\footnotetext{
${ }^{6}$ Matthiessen notes that "it seems plausible that some form of Phase I - protolanguage - is very old indeed, predating the evolution of the hominid line and thus extending back in time before the common ancestor" (Matthiessen 2006: 56).
} 
Palaeolithic revolution" and the emergence of the anatomically modern human and continues to our present time. From a sociological perspective, the first social formations were local groups of 100 to 500 members.

This systemic-functional perspective finds that the key motif in the evolution of language was the creation of meaning, suggesting that every evolutionary change expanded the meaning-making power. As Halliday says (2006), the meaning potential is something that has to be learnt and constructed, and grammar is the driving force because it has a special place as the source of energy for the semiotic process.

\subsection{Reassessing Luhmann's hypothesis on pre-linguistic communication from the standpoint of systemic-functional linguistics}

In light of the previous discussion, we can return to Luhmann's paragraph cited in the appendix. The sequence of recursive gestures that Luhmann mentions is most probably identifiable with Matthiessen's phase II, as it is in that moment that language started to acquire the capacity for the formation of sequences with a semantic structure. In contrast, in phase I there was no possibility of dialogue. From the point of view of social differentiation, Matthiessen relates this phase with the beginning of family-level group societies. In contrast, Luhmann signals the existence of relatively complex social orders characterised by hierarchies and individual partner preferences. In this instance, Luhmann is cognisant of not mentioning organisation through families, as this is a particular trait of segmentary societies. Therefore, one possibility would be that the scenario depicted by Luhmann represents the very beginning of a form of differentiation based on family before the consolidation of segmentary societies. From the viewpoint of metacommunication, it would be difficult to metacommunicate with the transitional language of phase II. At that moment, language expresses pragmatic ("somebody to do something") and mathetic functions (a learning function). In the examples provided by Halliday for these two types of macrofunctions $(2003,2006)$, we cannot find examples of metacommunication. Nevertheless, in phase II there is the possibility of dialogue, which implies the possibility of construing themes and, as a consequence, the formation of a rudimentary social memory. This can contradict Luhmann's statement: "It remains to be seen whether, under these circumstances, we can already speak of autopoietic closure of a social system independent of 
the course of life - for example, enduring beyond the death of whole generations" (2012: 124). If we suppose that with dialogue there can be formation of themes and semantics, the autopoietic closure and the endurance through generations could be, if not guaranteed, at least very likely. Summarising, the situation that Luhmann depicts cannot be directly identified with one of the phases presented by Matthiessen, but it is possible to place it in between phases I and II. In contrast, if we consider that Luhmann's scenario represents phase $\mathrm{I}$, autopoiesis becomes more improbable, as there is no possibility of dialogue and both the construction of themes and metacommunication become more questionable. Nevertheless, in phase I we cannot assume that these gestures could construct sequences. Moreover, this social order cannot be qualified as "relatively complex", as it would be one of the simplest ones in human (if we can talk about humans) history. In this sense, it is not possible to accept the presence of "hierarchies and individual partner preferences" (Luhmann, 2012: 123) as manifestations of some sort of social differentiation, because in segmentary societies there were no differences between members. Consequently, it is not possible to postulate that the form of societal differentiation prior to segmentary societies is more complex than segmentariness itself. In addition, we should also assume that this social order was not organised by families.

Regarding the problem of the phylogenetic evolution of language, there are some conflicting points between the systems' theoretical and systemicfunctional approaches. As has been said before, Luhmann says that the most important preparation for the evolution of language is the perception of perception and the perception of being perceived, and he emphasises the role played by gestures and sounds. In contrast, systemic-functional linguistics draws the attention to grammar as the key element in evolution. It is not perception of perception or the use of gestures and sounds, but grammar that expands the limits of meaning. Concerning meaning, there is a distinct difference between these two theories. In the first line of the paragraph quoted in the appendix, Luhmann says directly that a "pre-linguistic communication medium that did not yet constitute meaning can have lain only in the totality of the behavioral options of individuals in each other's presence" (Luhmann, 2012: 123). This can be due to the fact that Luhmann follows Mead's concept of "conversation of gestures". On the contrary, Halliday and Matthiessen consider that all three phases constitute meaning, even if the meaning potential increases with evolution. However, if we 
consider that this pre-language does not constitute meaning, this raises a new question about the "emergence" of meaning. From our previous analyses, we cannot deduce that it is the "emergence" of language as the element that endorses the "emergence" of meaning. In addition, if part of the discussion were about the definition of the social order that emerges out of this communication of gestures, there is no apparent reason to exclude this social order from the medium of meaning. The systemic-functional approach connects each species of the genus Homo to a form of language and, as a result, to meaning. We cannot envisage any consistent reason why Luhmann considered that the pre-linguistic medium could not constitute meaning, leaving outside the realm of meaning some sort of social order and pre-linguistic communication. In conclusion, we think that it is more coherent for systems theory to assume that the pre-linguistic communication medium constitutes meaning.

\section{Action and experience: the problem of the ontogenesis of language}

\subsection{A nativist approach to the ontogenesis of language: Srubar's criticism of Luhmann's approach to language}

The previous section dealt with the problem of the phylogenesis of language. In this section, we will turn our focus to ontogenesis. As we have already seen, the common point of departure for both these concepts is structural coupling. In the case of ontogenesis, Luhmann did not provide any particular hypothesis. This is one of the focuses of Srubar's (2005) criticism because, according to him, there are series of cognitive patterns that are ontogenetic and adhere to the analysis of lifeworld and that by no means follow a primarily linguistic form. These patterns do not stem from acts of perception as Luhmann (like Edmund Husserl) - in the opinion of Srubar (2005) - is disposed to accept, but they are coined by corporeality and action as interaction with things and others. As a result, the acquisition of language can be thought of as a process of translation of action schemes into linguistic ones. In this sense, language can be seen as a meaning system that projects phylogenetic structures of action, which are then adopted ontogenetically in contexts of action.

To hold these arguments, Srubar quotes the results of some research, departing from George Lakoff and Mark Johnson's analysis of the metaphor, which implies the translation of action schemes into linguistic forms. 
Citing the work of Jeff Greenberg among others, he indicates how language can express quantities, objects, acts or location in space and time through nouns, adjectives, verbs, adverbs and other constructions. Referencing creole language studies, Srubar stresses the presence of minimal grammatical structures that every language must have. These structural elements belong to linguistic forms near action. They are necessary to describe a situation of action, and they represent the temporal (verb tense), spatial-material (local prepositions, plural, quantities) and social (personal, reflexive, relative pronouns) dimensions of the field of action. In contrast to Luhmann and to systemic-functional linguistics, Srubar relies on nativist conceptions of language.

\subsection{The systemic-functional explanation of the ontogenesis of language}

Analysing the development of language in early childhood, Halliday (2003) finds a connection between the capacity of the child to move and experience and the language s/he employs. As a result, Halliday discovers that as the child learns to crawl, s/he can examine his/her environment obtaining a three-dimensional perspective. At the same time, the signs become organised in the sign system that we have viewed as protolanguage. Likewise, the final path to adult language starts when the child begins to walk, which is also the last phase in the dimensioning of the child's perception of the environment (Halliday, 2006). Most importantly, in adult language, grammar sets up a theory of experience, as grammar is the mechanism that transforms human experience into meaning, construing a universe of things and relationships and imposing categories on psychic perceptions of phenomena (Halliday, 1998). In the most general terms, grammar construes experience as process in the form of a clause.

Discussing the ineffability of grammatical categories, Halliday (2005d) indicates that there is no exact paraphrase of grammatical categories (e.g., subject, actor, theme, etc.), because they do not correspond to a languageindependent clustering of phenomena in our experience. They would be glossable only if language were a purely passive partner that only copies a reality. Nevertheless, language creates reality, and there is no model of experience prior to the linguistic categories, which model it. As a result, it is not possible to define these grammatical categories by relating them to some pre-existing model of experience, as Srubar seems to suggest. 
In this sense, we can doubt that there is a translation of non- and pre-linguistic cognition schemes in linguistic form, as Srubar indicates, because there is no model of experience before the linguistic categories. In addition, grammar does not represent action through its different dimensions, because there is no model to copy. In this instance, the category of language also involves that of protolanguage, so there is no room to consider human experience prior to any of the three stages of language descripted in section 3. In contrast, if we adopt a nativist viewpoint, most of the linguistic categories are not construed phylogenetically and ontogenetically, but they are innate structures of the human brain. As a result, language would not be an active but a passive participant in the semogenic process.

\subsection{The problem of action in Luhmann's theory and its relation to the ontogenesis of language}

Returning to Luhmann's systems theory, until now we have talked about action and experience (Erleben). This pair of concepts is interpreted in systems theory (Luhmann, 2012, 2013) as two possibilities of attribution for (human) behaviour. ${ }^{7}$ This distinction departs from the distinction in communication between information and utterance. Thus, when the accent is placed on information, the system interprets this process as experience (an attribution to the environment), while when the accent is placed on utterance, we have action (an attribution to the system itself). Therefore, according to this theory, action and experience are only attributions of behaviour and do not correspond to the operations of any system. Now, the question becomes: What is behaviour? Luhmann finds the answer in Maturana (Luhmann, 2012: 410). As maintained by the Chilean biologist (Maturana, 1982), an observer looks at an organism or living being as a unity that interacts with its environment. S/he only sees the organism's changes in position or form in the environment as reactions to the perturbations that have occurred in that environment or as a result of the organism's own internal dynamics. The organism's changes in form and position relative to its environment constitute its behaviour. Nevertheless, behaviour does not belong to the organism as a trait of some or all of its changes of state. Behaviour

\footnotetext{
${ }^{7}$ In a text from 1978, Luhmann (1981) talks about human behaviour, but the adjective "human" will be erased from Die Gesellschaft der Gesellschaft. In that text, Luhmann also indicates that both experience and action are cases of conditioned bodily and sequential performances. Another common feature is that both are intentional processes.
} 
is only the relationship between an organism and the environment in which an observer distinguishes and observes it. As a result, a system that is part of the organism (Maturana here talks about the case of the nervous system) does not produce any behaviour; it only takes part in the dynamics of change in the organism. This means that behaviour is the construction of the observer, who cannot observe the organism's internal changes of state. Consequently, s/he names those changes in position and form (the only events that $\mathrm{s} / \mathrm{h}$ can register) "behaviour of organism X". Therefore, as a mere construction of an observer, behaviour does not correspond exactly to any operation of a system. It would correspond, rather, to the result of the operativity of a series of systems that are structurally coupled.

Recapitulating, action and experience are attributions of behaviour, which, in turn, is constructed by an observer. Accordingly, action and experience are the names given to the observable results of the structurally coupled operativity of social, psychic and living systems. What we cannot do here is try to look for the operative correspondence to action or experience, as these are just the results of a process of observation that has no access to the operativity of the systems.

One focus of Srubar's (2005) critiques is action. He understands it to be a third dimension of the lifeworld in addition to consciousness and communication. Srubar $(2009)^{8}$ coined the concept of the action-thoughtlanguage connection (HDS-Zusammenhang), as these represent three moments of the human approach to the world (Weltzugang) and are, therefore, associated with each other. In addition, following Alfred Schütz, he understands action as Wirken, or interaction with objects and with others, to which the primary structures of experience of the approach to the world trace back. In this sense, Wirken and its results are associated (as experience) with intentional, conscious acts.

As we have seen, action is not completely ignored by Luhmann. It is true that with Luhmann's approach, action loses its ontological ground, and it cannot be equated to consciousness and communication, as Srubar suggests. On the other hand, Luhmann does not deny that action and experience are intentional processes. The main problem here is that Srubar insists on considering action to be a moment in the human approach to the world, strongly associating it to consciousness. Even if Luhmann talked

\footnotetext{
${ }^{8}$ See chapter: "Handeln, Denken, Sprechen. Der Zusammenhang ihrer Form als genetischer Mechanismus der Lebenswelt".
} 
previously about human behaviour, the attribute "human" refers here not only to consciousness, but also to bodily performances, which means that living systems (not to mention social systems) are also involved in the concept of behaviour.

If we put these "ontological" discussions aside, Srubar's main point on ontogenesis and phylogenesis of language is the pre-eminence of action and the translation of action schemes into linguistic ones. This is not necessarily in contradiction with Luhmann's approach. Luhmann did not accept the nativist perspective, which Srubar is ready to incorporate. Introducing the systemic-functional approach, we have tried to reject both of Srubar's hypotheses indicated in subsection 4.2.

Regarding the ontogenesis of language, our hypothesis is that systemic-functional linguistics can be useful to fill the gap left by systems theory. A delicate issue here is the relationship between grammar and experience that Halliday hypothesised. As previously mentioned, Halliday states that grammar construes experience as process in the form of a clause. This is in accordance with Luhmann and Maturana's interpretation of behaviour (and experience as an attribution of behaviour) as the construction of an observer. Thus, this can strengthen Luhmann's argument that action and experience are attributions of behaviour. In this process of attribution, which is a communicative process, the observer transforms a series of observations concerning some changes in position or form of a system (or of a conglomerate of systems as in the human body) into an utterance (linguistically constructed), which indicates that the reason for these changes are either in the environment (experience) or in the system (action).

\section{Conclusions}

Systems theory approaches the problems of ontogenesis and phylogenesis of language through the concepts of structural coupling and co-evolution between social and psychic systems. With respect to phylogenesis, we have seen that Luhmann departs from a scenario dominated by a pre-linguistic communication medium that does not constitute meaning. This sort of communication, based in sequences of recursive gestures, allows the emergence of a certain social order. One problem is the impossibility of identifying this social order by one of the primary forms of societal differentiation, because this social order is prior to all forms of societal differentiation. 
On the other hand, Luhmann detects in this emerging social order the presence of sequences of recursive gestures. As Matthiessen indicates, the possibility of dialogue is a property of a transitional language, which appears in the context of a societal structuration organised around families. Another condition that Luhmann introduces in this situation is the impossibility of metacommunication, which is a condition for the autopoietic closure of social systems. Even accepting the impossibility of metacommunication, the existence of dialogue could have allowed the construction of themes and, as a consequence, the formation of a rudimentary social memory. In this way, the survival of the communicative system can be ensured. An additional point of controversy is meaning. If we consider that this pre-language does not constitute meaning, this raises a new question about the "emergence" of meaning. In addition, there is no apparent reason to exclude the social order based on pre-linguistic communication from the medium of meaning.

Regarding ontogenesis, the point of departure of our analysis was Srubar's criticism of Luhmann's interpretation of language, according to which the acquisition of language can be thought of as a process of translation of action schemes into linguistic ones. In contrast to this, systemic-functional linguistics denies the possibility of a translation of non- and pre-linguistic cognition schemes into linguistic form because there is no model of experience previous to the linguistic categories. In addition, grammar does not represent action through its different dimensions.

Our position here is that systemic-functional linguistics can be useful to fill the gap regarding the ontogenesis of language left by systems theory. Halliday states that grammar construes experience as process in the form of a clause, which is in accordance with Luhmann and Maturana's interpretation of behaviour as the construction of an observer. As a result, this point can strengthen Luhmann's interpretation of action and experience as attributions of behaviour. Through this communicative process of attribution, the observer transforms his/her operations of observation related to the changes that another system undergoes into linguistically construed utterances. When the observer understands that the cause of these changes is located in the environment, the system "experiences" these changes, while when the cause is identified with the system, it is the system itself that produces the changes (action). 


\section{REFERENCES}

Baraldi, Claudio (1993). "Structural Coupling: Simultaneity and Difference between Communication and Thought", Communication Theory, 3 (2): 112-129. doi: 10.1111/j.1468-2885.1993.tb00061.x

De Saussure, Ferdinand (1995). Cours de linguistique générale. Paris: Éditions Payot \& Rivages.

Deacon, Terrence (1997). The Symbolic Species: The Co-Evolution of Language and the Brain. New York and London: W. W. Norton \& Company.

Eggins, Suzanne (2004). An Introduction to Systemic Functional Linguistics. New York: Continuum.

Halliday, Michael (1978). Language as Social Semiotic: The Social Interpretation of Language and Meaning. Baltimore: University Park Press.

Halliday, Michael (1998). "Things and Relations: Regrammaticising Experience as Technical Knowledge”, in: James R. Martin and Robert Veel (eds). Reading Science: Critical and Functional Perspectives on Discourses of Science. London and New York: Routledge, pp. 185-235.

Halliday, Michael (2003). The Language of Early Childhood. London and New York: Continuum.

Halliday, Michael (2004). "Things and Relations: Regrammaticizing Experience as Technical Knowledge”, in: Jonathan J. Webster (ed.). The Language of Science - M.A.K. Halliday. London and New York: Continuum, pp. 49-101.

Halliday, Michael (2005a). "Grammar and Daily Life: Concurrence and Complementarity", in: Jonathan J. Webster (ed.). On Grammar - M.A.K. Halliday. London and New York: Continuum, pp. 369-383.

Halliday, Michael (2005b). "Modes of Meaning and Modes of Expression: Types of Grammatical Structure and Their Determination by Different Semantic Functions", in: Jonathan J. Webster (ed.). On Grammar - M.A.K. Halliday. London and New York: Continuum, pp. 196-218.

Halliday, Michael (2005c). "On Grammar and Grammatics", in: Jonathan J. Webster (ed.). On Grammar - M.A.K. Halliday. London and New York: Continuum, pp. 384-418.

Halliday, Michael (2005d). "On the Ineffability of Grammatical Categories", in: Jonathan J. Webster (ed.). On Grammar - M.A.K. Halliday. London and New York: Continuum, pp. 291-322.

Halliday, Michael (2005e). "Some Notes on 'Deep' Grammar", in: Jonathan J. Webster (ed.). On Grammar - M.A.K. Halliday. London and New York: Continuum, pp. 106-117.

Halliday, Michael (2006). "On Grammar as the Driving Force from Primary to Higher-Order Consciousness", in: Geoff Williams and Annabelle Lukin (eds). The Development of Language: Functional Perspectives on Species and Individuals. London and New York: Continuum, pp. 15-44.

Halliday, M. A. K. and Matthiessen, Christian M. I. M. (1999). Construing Experience Through Meaning: A Language-based Approach to Cognition. London and New York: Continuum. 
Luhmann, Niklas (1981). Soziologische Aufklärung 3: Soziales System, Gesellschaft, Organisation. Opladen: Westdeutscher Verlag.

Luhmann, Niklas (1995a). Social Systems. Stanford: Stanford University Press.

Luhmann, Niklas (1995b). Soziologische Aufklärung 6: Die Soziologie und der Mensch. Opladen: Westdeutscher Verlag.

Luhmann, Niklas (1997). Die Gesellschaft der Gesellschaft (2 Bd.). Frankfurt am Main: Suhrkamp Verlag.

Luhmann, Niklas (1999). "Sign as Form", in: Dirk Baecker (ed.). Problems of Form. Stanford: Stanford University Press, pp. 46-63.

Luhmann, Niklas (2004). Einführung in die Systemtheorie. Heidelberg: Carl-AuerSysteme Verlag.

Luhmann, Niklas (2012). Theory of Society, Voume 1. Stanford: Stanford University Press.

Luhmann, Niklas (2013). Theory of Society, Voume 2. Stanford: Stanford University Press.

Matthiessen, Christian (2006). "The Evolution of Language: A Systemic Functional Exploration of Phylogenetic Phases", in: Geoff Williams and Annabelle Lukin (eds). The Development of Language: Functional Perspectives on Species and Individuals. London and New York: Continuum, pp. 45-90.

Maturana, Humberto (1982). "Reflexiones: Aprendizaje o Deriva Ontogénica", Archivos de Biología Y Medicina Experimentales, 15: 261-271.

Mead, George H. (1972). Mind, Self and Society: From the Standpoint of a Social Behaviorist. Chicago and London: The University of Chicago Press.

Spencer-Brown, George (1972). Laws of Form. New York: The Julian Press.

Srubar, Ilja (2005). "Sprache und strukturelle Kopplung. Das Problem der Sprache in Luhmanns Theorie", Kölner Zeitschrift für Soziologie und Sozialpsychologie, 57 (4): 599-623. doi: 10.1007/s11577-005-0217-2

Srubar, Ilja (2009). Kultur und Semantik. Wiesbaden: VS Verlag.

Urban, Michael (2009). Form, System und Psyche. Zur Funktion von psychischem System und struktureller Kopplung in der Systemtheorie. Wiesbaden: VS Verlag.

\section{APPENDIX - Luhmann's fragment on pre-linguistic communication}

A pre-linguistic communication medium that did not yet constitute meaning can have lain only in the totality of the behavioral options of individuals in each other's presence. Movement in space will have played a considerable role. Following George Herbert Mead, we could also speak of a recursive sequence of gestures, in which not the single act but recursivity (connection with what has preceded) prompts emergent effects. In such episodic contexts, we also find species-specific signals, which are, however, of very limited use. Signals are not yet signs, do not yet point to something else; they are only a factor activating "anticipatory reactions" 
owing to typical, repeated complexes of present and future events, which are, however, not recognized as complexes. Such conditions can enable the morphogenesis of relatively complex social orders if reactive patterns of behavior are reapplied to their own outcomes. Participants do not need to be able to recognize the structures that consequently emerge and to react to them. The potential for form building must therefore have been correspondingly limited, but apparently sufficient to establish hierarchies and individual partner preferences. In the pre-linguistic field, indeed, even in relations between humans and animals, we find what is probably the most important preparation for the evolution of language: the perception of perception and, in particular, the perception of being perceived. Even in developed societies, even today, these are still indispensable forms of sociality, especially in relations between the sexes. At this level, sociality uses the complexity and focusability of perception and generates a present-almost without a future. Even if we can assume this as, so to speak, a pre-prehistorical given, and accordingly that life in society adapted to this possibility, this social state of affairs would have allowed of no metacommunication, no communication relating to communication; no, for example, confirmation of the receipt of an utterance, no repetition of the same utterance, no development of sequential, "punctuated" complexity in which communication presupposes that it has already operated successfully with other content. It remains to be seen whether, under these circumstances, we can already speak of autopoietic closure of a social system independent of the course of life-for example, enduring beyond the death of whole generations - and whether and to what extent we can already speak of "language" in Humberto Maturana's sense, of coordinating the coordination of living beings' behavior in their individual existences. In any case, language in the usual meaning of the term with its clear preference for acoustic media and the optical media deriving from them is a singular historical construction of evolution based on a stringent selection of resources. However, this is not the place to launch into a study of the evolution of language; I merely assume that, as in all evolution of autopoietic systems, a sort of auxiliary construction made takeoff possible. The use of gestures and sounds as signs presumably played a role. (Luhmann, 2012: 123-124) 


\title{
Promišljanje teorije filogeneze $\mathrm{i}$ ontogeneze jezika Niklasa Luhmanna u svjetlu sistemsko-funkcionalne lingvistike
}

\author{
Santiago Gabriel CALISE \\ Nacionalno vijeće za znanstvena i tehnička istraživanja, Istraživački institut \\ Gino Germani, Fakultet društvenih znanosti, Sveučilište u Buenos Airesu, \\ Argentina \\ c_santiago_g2000@yahoo.com.ar
}

U radu se obrađuju problemi filogeneze i ontogeneze jezika odmicanjem od opće hipoteze Niklasa Luhmanna o suevoluciji psihičkih i društvenih sustava. U pogledu filogeneze jezika, naglasak je u Luhmannovoj teoriji smješten na "predjezični medij komunikacije« sačinjen od gesta, koji je mogao biti temelj poticanja evolucije jezika. Ta vrsta komunikacije omogućuje pojavu određenoga društvenog poretka. Problem je bio u nemogućnosti identificiranja toga društvenog poretka jednim od primarnih oblika socijetalne diferencijacije. Autor ovog rada nastojao je protumačiti u kojim se socijetalnim kontekstima »pojavljuje« predjezik. U tu se svrhu oslonio na sistemsko-funkcionalnu lingvistiku Michaela Hallidaya. U pogledu ontogeneze jezika, pozornost je usmjerena na koncepte djelovanja i iskustva. Kao polazna točka za to poslužila je kritika Ilje Srubara upućena Luhmannovoj teoriji jezika, prema kojoj se na stjecanje jezika može gledati kao na proces prevođenja shema djelovanja u jezične sheme. To uključuje nativističko viđenje jezika koje su odbacili i Luhmann i Halliday, od kojih je potonji sugerirao kako je nemoguće govoriti o prevođenju nejezičnih i predjezičnih spoznajnih shema u jezični oblik, jer ne postoji model iskustva koji prethodi jezičnim kategorijama. Autor je i ovdje nastojao pokazati da sistemsko-funkcionalna lingvistika može biti korisna u popunjavanju praznina koje je u tumačenju ontogeneze jezike za sobom ostavila Luhmannova sistemska teorija.

Ključne riječi: jezik u sistemskoj teoriji, Luhmann, ontogeneza jezika, filogeneza jezika, distinkcija djelovanja i iskustva, sistemsko-funkcionalna lingvistika 